\title{
SIFAT KEMONOTONAN PADA JUMLAH TRAPESIUM DARI HAMPIRAN FUNGSI-FUNGSI KONVEKS
}

\author{
Yudasril $^{1, a)}$, Berlian Setiawaty ${ }^{2, b)}$ \\ 1,2Program Studi Matematika Terapan, FMIPA-Institut Pertanian Bogor \\ Email: a)mate2_yudasril@apps.ipb.ac.id ${ }^{\text {b) }}$ berlianse@apps.ipb.ac.id
}

\begin{abstract}
Besides Darboux sum, trapezium sum can be used too for estimating the area under the curve of a nonnegative real function $f$ on the interval $[a, b]$. For all partition $P_{n}$ that divide the interval $[a, b]$ into $n$ equal length subintervals, formed an approach of integral value or the area under the $f$-curve on $[a, b]$ that is, trapezium sum $T_{n}(f)$. In this paper, it will be shown that there is a piecewise linear function $g$ approaching convex function $f$ such that the tail of the sequence of the trapezium sum sequence $\left\{T_{n}(g)\right\}_{n=1}^{\infty}$ is increasing.
\end{abstract}

Keywords: sequence, tail of sequence, convex function, trapezium sum, increasing.

\begin{abstract}
ABSTRAK
Selain jumlah Darboux, jumlah trapesium juga dapat digunakan dalam menghampiri luas daerah di bawah kurva dari suatu fungsi $f$ real taknegatif pada suatu interval $[a, b]$. Untuk setiap partisi $P_{n}$ yang membagi interval $[a, b]$ menjadi $n$ subinterval dengan jarak yang sama, dibentuk suatu pendekatan dari nilai integral atau luas di bawah kurva $f$ pada $[a, b]$ yakni, jumlah trapesium $T_{n}(f)$. Dalam tulisan ini, akan diperlihatkan bahwa terdapat suatu fungsi linear sesepenggal $g$ yang menghampiri fungsi konveks $f$ sedemikian sehingga ekor barisan dari barisan jumlah trapesium $\left\{T_{n}(g)\right\}_{n=1}^{\infty}$ adalah monoton naik.
\end{abstract}

Kata kunci: barisan, ekor barisan, fungsi konveks, jumlah trapesium, monoton naik.

\section{PENDAHULUAN}

Luas daerah di bawah kurva dari suatu fungsi real taknegatif pada sebuah interval yang tertutup dan terbatas dari himpunan bilangan real merupakan definisi tentang integral tentu yang dituturkan oleh Bernhard Riemann pada tahun 1850 (Bartle dan Shertbert, 2010). Selain jumlah Darboux, jumlah trapesium juga dapat digunakan dalam menghampiri luas daerah tersebut. Walaupun jumlah Darboux lebih mudah untuk digunakan, jumlah trapesium ini lebih unggul dalam menghampiri nilai integral dari fungsi-fungsi yang well behaved (Bennet dan Jameson, 2000).

Misalkan $f$ adalah suatu fungsi bernilai real yang terdefinisi dan kontinu pada interval $[a, b]$. Untuk setiap partisi $P_{n}$ yang membagi interval $[a, b]$ menjadi $n$ subinterval dengan jarak yang sama, dibentuk suatu pendekatan dari nilai integral atau luas di bawah kurva $f$ pada $[a, b]$ yakni, jumlah trapesium $T_{n}(f)$.

Kyrezi (2010) menunjukkan bahwa sebarang fungsi $f$ dapat dihampiri oleh suatu fungsi linear sesepenggal $g$ pada $[a, b]$, sehingga ekor barisan Jumlah Darboux atas dari fungsi $g$ terhadap partisi $P_{n}$ bersifat monoton naik. Selain itu, dalam penelitian Bennet 
dan Jameson (2000) menyatakan bahwa jika sebarang fungsi $f$ adalah konveks dan diketahui $f^{\prime}$ konveks, maka barisan dari jumlah trapesium $\left\{T_{n}(f)\right\}_{n=1}^{\infty}$ adalah monoton turun, sehingga ekor barisannya juga monoton turun. Namun, pada penelitian ini akan diperlihatkan bahwa terdapat fungsi $g$ yang menghampiri fungsi konveks $f$ sedemikian sehingga ekor barisan dari barisan jumlah trapesium $\left\{T_{n}(g)\right\}_{n=1}^{\infty}$ adalah monoton naik. Hal ini terinspirasi dari tulisan Kyrezi (2010) yang berjudul "Monotonicity properties of Darboux sums".

\section{KONSTRUKSI EKOR BARISAN JUMLAH TRAPESIUM DARI HAMPIRAN FUNGSI $\boldsymbol{f}$}

Pertama-tama, tetapkan bahwa $f$ adalah fungsi bernilai real yang terdefinisi dan kontinu pada interval terbatas dan tertutup $[a, b]$, atau $f \in C[a, b]$ dengan norm $\|f\|_{\infty}=$ $\sup \{|f(x)|: x \in[a, b]\}$ (Chatterjee, 2007). Kemudian, akan diarahkan bentuk dari hampiran fungsi $f$ serta ekor barisan dari jumlah trapesium yang selanjutnya akan disajikan dalam suatu proposisi.

\subsection{Hampiran Fungsi $f$}

Sebelum mengonstruksi hampiran dari fungsi $f$, berikut diberikan beberapa definisi dan teorema mengenai fungsi $f$ dan fungsi konveks yang berguna dalam proses pembuktian dan pengonstruksian fungsi hampirannya.

Definisi 1 (Bartle dan Shertbert, 2010) $f$ disebut fungsi konveks pada $[a, b]$ jika $\forall t \in$ $[0,1]$ dan $\forall x_{1}, x_{2} \in[a, b]$ memenuhi

$$
f\left((1-t) x_{1}+t x_{2}\right) \leq(1-t) f\left(x_{1}\right)+t f\left(x_{2}\right) .
$$

Secara geometris, fungsi yang konveks berada di atas semua garis singgungnya pada interval $[a, b]$ (Stewart, 2010).

Definisi 2 (Bartle dan Shertbert, 2010) Misalkan interval $I=[a, b]$. Fungsi $f: I \rightarrow R$ dikatakan linear sesepenggal pada I jika I adalah gabungan berhingga dari intervalinterval yang saling lepas $I_{1}, I_{2}, \ldots, I_{n}$, sedemikian sehingga fungsi $f$ adalah fungsi linear pada setiap interval $I_{k}$ dengan $k=1,2,3, \ldots, n$.

Teorema 1 (Cheney dan Kincaid, 2008) Setiap minimum lokal dari fungsi konveks $f \in$ $C[a, b]$ adalah suatu minimum global dari $f$ pada $[a, b]$.

Teorema 2 (Bartle dan Shertbert, 2010) Misalkan $f \in C[a, b]$, maka $f$ kontinu seragam pada $[a, b]$.

Selanjutnya, secara matematis untuk menyatakan bahwa hampiran dari sebarang fungsi konveks $f$ yakni $g \in C[a, b]$ yang linear sesepenggal dapat ditulis sebagai berikut:

$$
\|f-g\|_{\infty}<\varepsilon, \forall \varepsilon>0 \text {. }
$$

\subsection{Ekor Barisan dari Jumlah Trapesium}

Berikut diberikan definisi mengenai jumlah trapesium dan kemudian dikonstruksi partisi-partisi yang akan digunakan dalam proses pembuktian.

Definisi 3 (Cheney dan Kincaid, 2008) Jumlah trapesium dari suatu fungsi $f \in C[a, b]$ yang berkorespondensi terhadap $P=\left\{\left[x_{i-1}, x_{i}\right]\right\}_{i=1}^{n}$ adalah:

$$
T(f, P)=\frac{1}{2} \sum_{i=1}^{n}\left(x_{i}-x_{i-1}\right)\left(f\left(x_{i-1}\right)+f\left(x_{i}\right)\right) \text {. }
$$


Selanjutnya, dikonstruksi partisi $P_{n}$ dari $[a, b]$ dengan subinterval-subinterval dari $[a, b]$ terhadap $P_{n}$ memiliki panjang yang sama yakni sebesar $\frac{b-a}{n}$, sehingga didapat $P_{n}=$ $\left\{x_{j}=a+j \frac{b-a}{n} \mid 0 \leq j \leq n\right\}$. Oleh sebab itu, berdasarkan Definisi 1 diperoleh jumlah trapesium terhadap partisi $P_{n}$, yaitu

$$
T_{n}(f)=\frac{b-a}{n} \sum_{i=1}^{n} \frac{\left(f\left(x_{i-1}\right)+f\left(x_{i}\right)\right)}{2} .
$$

Ekor barisan untuk suatu $N \in \mathbb{N}$ dari barisan jumlah trapesium $\left\{T_{n}(f)\right\}_{n=1}^{\infty}$ adalah $\left\{T_{n}(f)\right\}_{n=N}^{\infty}$ berdasarkan definisi ekor barisan dalam buku Introduction to Real Analysis oleh Bartle dan Shertbert pada tahun 2010. Selanjutnya, secara matematis untuk menyatakan bahwa ekor barisan tersebut monoton naik dapat ditulis sebagai berikut:

$$
\exists N \in \mathbb{N}, \forall n \geq N, T_{n}(g)<T_{n+1}(g) .
$$

\section{HASIL DAN PEMBAHASAN}

\subsection{Kemonotonan Ekor Barisan Jumlah Trapesium}

Terdapat fungsi kontinu $g$ bernilai real dan linear sesepenggal pada $[a, b]$ yang dekat dengan sebarang fungsi $f$ yang kontinu dan konveks bernilai real pada $[a, b]$. Kemudian, jumlah trapesium dari $g$ tersebut yang berkorespondensi terhadap partisi $P_{n}$, bersifat monoton naik $\forall n \geq N, N \in \mathbb{N}$. Pernyataan tersebut dapat disajikan dan dibuktikan pada Proposisi 1.

Proposisi 1 Misalkan $f \in C[a, b]$ adalah fungsi kontinu dan konveks. $\forall \varepsilon>0, \exists N \in$ $\mathbb{N}$ sedemikian sehingga $\forall n \geq N$ terdapat fungsi yang linear sesepenggal $g \in C[a, b]$ sedemikian sehingga

$$
\|f-g\|_{\infty}<\varepsilon
$$

dan

$$
T_{n}(g)<T_{n+1}(g)
$$

Bukti Proposisi 1:

Diberikan sebarang $\varepsilon>0$.

Diketahui bahwa $f \in C[a, b]$, sehingga berdasarkan Teorema $2, f$ adalah fungsi yang kontinu seragam pada $[a, b]$. Oleh karena itu, terdapat $\delta=\min \left(\frac{1}{2}, \delta(\varepsilon)\right)>0$ sedemikian sehingga untuk setiap $x, y \in[a, b]$ dan $|x-y|<\delta$, diperoleh $\mid f(x)-$ $f(y) \mid<\frac{\varepsilon}{4}$. Pilih $N=N(\varepsilon)>\frac{(b-a)}{\delta}$ yang mengakibatkan $\frac{(b-a)}{N}<\delta$ dan selanjutnya ambil sebarang $n \geq N$.

Misalkan partisi-partisi

$$
\begin{gathered}
P_{n}=\left\{x_{j}=a+j \frac{(b-a)}{n}: 0 \leq j \leq n\right\}, \\
P_{n+1}=\left\{y_{j}=a+j \frac{(b-a)}{n+1}: 0 \leq j \leq n+1\right\} .
\end{gathered}
$$


Perlu diperhatikan bahwa $x_{j-1}<y_{j}<x_{j}, 1 \leq j \leq n$.

Konstruksi fungsi $g \in C[a, b]$ sebagai berikut:

Pertama, definisikan

$$
f\left(x_{j}\right)=p_{j}, 0 \leq j \leq n .
$$

Karena $f$ konveks dan kontinu pada $[a, b]$ sehingga menurut Teorema 1 terdapat minimum global dari $f$ pada $[a, b]$, yakni katakanlah $f(c), c \in[a, b]$. Selain itu, $f$ turun pada $[a, c)$ dan naik pada $(c, b]$. Selanjutnya, partisi-partisi (1) masing-masing dapat dibentuk menjadi tiga subpartisi seperti berikut,

$$
\begin{aligned}
P_{n} & =P_{n}^{1} \cup P_{n}^{2} \cup P_{n}^{3} \\
& =\left\{x_{0}, x_{1}, \ldots, x_{k}\right\} \cup\left\{x_{k}, x_{k+1}\right\} \cup\left\{x_{k+1}, x_{k+2}, \ldots, x_{n}\right\}, \\
P_{n+1} & =P_{n+1}^{1} \cup P_{n+1}^{2} \cup P_{n+1}^{3} \\
& =\left\{y_{0}, \ldots, y_{k}, x_{k}\right\} \cup\left\{x_{k}, y_{k+1}, x_{k+1}\right\} \cup\left\{x_{k+1}, y_{k+2}, \ldots, y_{n+1}\right\},
\end{aligned}
$$

di mana $c \in\left[x_{k}, x_{k+1}\right]$ untuk suatu $k \in \mathbb{N}$.

Misalkan $v=f(c)$, serta $p_{k}<p_{k}^{*}<p_{k-1}$ dan $p_{k+1}<p_{k+1}^{*}<p_{k+2}$.

Kemudian, didefinisikan fungsi $g \in C[a, b]$ sebagai fungi kontinu dengan

$$
\begin{gathered}
g\left(x_{j-1}\right)=g\left(y_{j}\right)=p_{j-1}, j=1,2, \ldots, k, \\
g\left(x_{k}\right)=p_{k}^{*}, \quad g\left(y_{k+1}\right)=v, \quad g\left(x_{k+1}\right)=p_{k+1}^{*}, \\
g\left(y_{j}\right)=g\left(x_{j}\right)=p_{j}, j=k+2, k+3, \ldots, n
\end{gathered}
$$

dan $g$ merupakan fungsi linear pada interval $I_{j}^{1}=\left[x_{j-1}, y_{j}\right]$ dan $I_{j}^{2}=\left[y_{j}, x_{j}\right], j=$ $0,1,2, \ldots, n$, di mana $p_{k}^{*}$ terletak pada garis yang melewati titik $\left(y_{k}, d_{k-1}\right)$ dan $\left(y_{k+1}, v\right)$, serta $p_{k+1}^{*}$ pada garis yang melewati titik $\left(y_{k+1}, v\right)$ dan $\left(y_{k+2}, p_{k+2}\right)$. Karena $[a, b]=$ $\bigcup_{j=1}^{n}\left(I_{j}^{1} \cup I_{j}^{2}\right)$, maka berdasarkan Definisi 2 fungsi $g:[a, b] \rightarrow \mathbb{R}$ adalah linear sesepenggal pada $[a, b]$. Fungsi $g$ dapat diilustrasikan seperti pada Gambar 1 . 


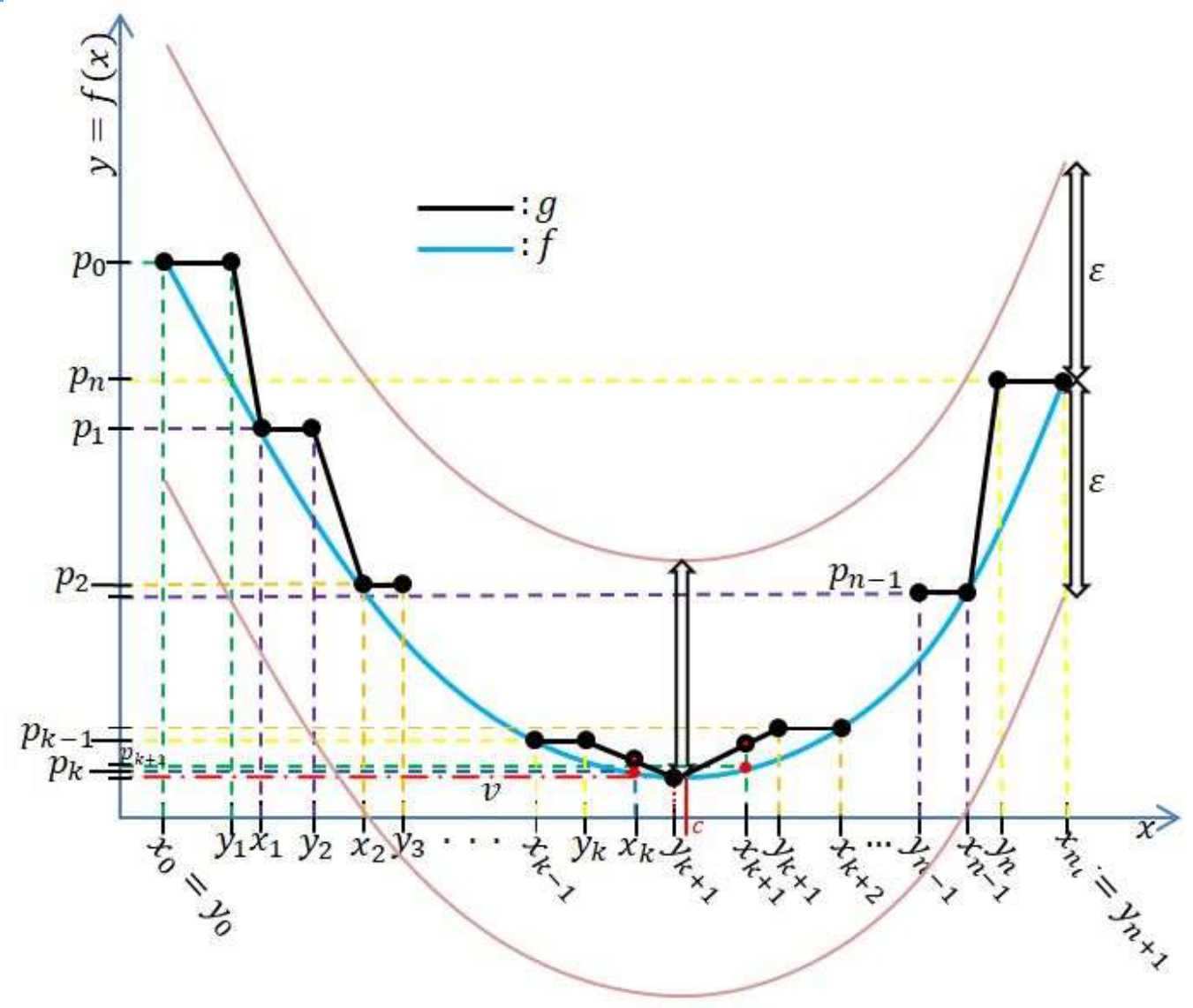

Gambar 1 Ilustrasi grafik fungsi $g$ pada $f$ yang konveks

Perhatikan bahwa untuk $=1,2, \ldots, n,\left|p_{j-1}-p_{j}\right|<\frac{\varepsilon}{5}$, sebab

$$
\begin{aligned}
\left|x_{j}-x_{j-1}\right| & =\left|\left(a+j \frac{(b-a)}{n}\right)-\left(a+(j-1) \frac{(b-a)}{n}\right)\right| \\
& =\frac{(b-a)}{n} \\
& \leq \frac{(b-a)}{N} \\
& <\delta .
\end{aligned}
$$

Hal ini juga mengakibatkan $\left|p_{j-1}-f\left(y_{j}\right)\right|<\frac{\varepsilon}{5},\left|p_{j}-f\left(y_{j}\right)\right|<\frac{\varepsilon}{5},\left|p_{k}-v\right|<\frac{\varepsilon}{5}$, dan $\left|p_{k+1}-v\right|<\frac{\varepsilon}{5}$.

Pertama, akan dibuktikan bahwa $\|f-g\|_{\infty}<\epsilon$, dan $\|f-g\|_{\infty}=\sup \{|f(x)-g(x)|$ : $x \in[a, b]\}$. Ambil sebarang $x \in[a, b]$, sehingga $x$ dapat berada pada $\left[a, y_{k}\right],\left(y_{k}, y_{k+2}\right)$, ataupun $\left[y_{k+2}, b\right]$.

Jika $x \in\left[a, y_{k}\right] \subset[a, c)$, jelas bahwa $x \in\left[x_{j-1}, x_{j}\right]$ untuk suatu $j \in \mathbb{N}, 1 \leq j \leq k-1$ 
atau $x \in\left[x_{k-1}, y_{k}\right]$ dan karenanya $p_{j} \leq g(x) \leq p_{j-1}$. Kemudian, pilih $y=x_{j}$ untuk $1 \leq j \leq k$ dan diperoleh

$$
\begin{gathered}
|f(y)-g(x)| \leq\left|f\left(x_{j}\right)-p_{j-1}\right|=\left|p_{j}-p_{j-1}\right|<\frac{2 \varepsilon}{5}, \\
|f(x)-f(y)| \leq\left|f\left(x_{j-1}\right)-f\left(x_{j}\right)\right| \leq\left|p_{j-1}-p_{j}\right|<\frac{\varepsilon}{5} .
\end{gathered}
$$

Jika $x \in\left(y_{k}, y_{k+2}\right)$, jelas bahwa $x \in\left(y_{k}, y_{k+1}\right] \subset[a, c)$ dan dengan memilih $y=y_{k+1}$, diperoleh

$$
\begin{gathered}
|f(y)-g(x)|<\left|f\left(y_{k+1}\right)-p_{k-1}\right| \leq\left|v-p_{k-1}\right| \leq\left|v-p_{k}\right|+\left|p_{k}-p_{k-1}\right|<\frac{2 \varepsilon}{5}, \\
|f(x)-f(y)|<\left|f\left(y_{k}\right)-f\left(y_{k+1}\right)\right| \leq\left|f\left(y_{k}\right)-p_{k}\right|+\left|p_{k}-f\left(y_{k+1}\right)\right|<\frac{2 \varepsilon}{5},
\end{gathered}
$$

atau $x \in\left(y_{k+1}, y_{k+2}\right) \subset(c, b]$ dan dengan memilih $y=y_{k+1}$, diperoleh

$$
|f(y)-g(x)|<\left|f\left(y_{k+1}\right)-p_{k+2}\right| \leq\left|v-p_{k+2}\right| \leq\left|v-p_{k+1}\right|+\left|p_{k+1}-p_{k+2}\right|<\frac{2 \varepsilon}{5},
$$

$|f(x)-f(y)|<\left|f\left(y_{k+2}\right)-f\left(y_{k+1}\right)\right| \leq\left|f\left(y_{k+2}\right)-p_{k+1}\right|+\left|p_{k+1}-f\left(y_{k+1}\right)\right|<\frac{2 \varepsilon}{5}$.

Dan jika $x \in\left[y_{k+2}, b\right] \subset(c, b]$, jelas bahwa $x \in\left[x_{j-1}, x_{j}\right]$ untuk suatu $j \in \mathbb{N}, k+3 \leq$ $j \leq n$ atau $x \in\left[y_{k+2}, x_{k+2}\right]$ dan karenanya $p_{j-1} \leq g(x) \leq p_{j}$. Kemudian, pilih $y=$ $x_{j-1}$ untuk $1 \leq j \leq k$ dan diperoleh

$$
\begin{gathered}
|f(y)-g(x)| \leq\left|f\left(x_{j-1}\right)-p_{j}\right|=\left|p_{j-1}-p_{j}\right|<\frac{2 \varepsilon}{5} \\
|f(x)-f(y)| \leq\left|f\left(x_{j}\right)-f\left(x_{j-1}\right)\right| \leq\left|p_{j-1}-p_{j}\right|<\frac{2 \varepsilon}{5} .
\end{gathered}
$$

Dengan menggunakan ketiga fakta di atas, maka $\forall x \in[a, b]$,

$$
|f(x)-g(x)| \leq|f(x)-f(y)|+|f(y)-g(x)|<\frac{4 \varepsilon}{5} .
$$

Kesimpulannya, $\|f-g\|_{\infty}=\sup \{|f(x)-g(x)|: x \in[a, b]\} \leq \frac{4 \varepsilon}{5}<\varepsilon$.

Selanjutnya akan dibuktikan bahwa $T_{n}(g)<T_{n+1}(g)$. Sebelum itu, berdasarkan subpartisi-subpartisi (2) dan (3) serta menggunakan Definisi 3, pertama akan diperlihatkan bahwa $T\left(g, P_{n}^{1}\right)-T\left(g, P_{n+1}^{1}\right)<0$.

$$
\begin{aligned}
& 2 T\left(g, P_{n}^{1}\right)-2 T\left(g, P_{n+1}^{1}\right) \\
& =\frac{b-a}{n} \sum_{i=1}^{k}\left(g\left(x_{i-1}\right)+g\left(x_{i}\right)\right)-\frac{b-a}{n+1} \sum_{i=1}^{k}\left(g\left(y_{i-1}\right)+g\left(y_{i}\right)\right)
\end{aligned}
$$




$$
\begin{aligned}
& -\left(x_{k}-y_{k}\right)\left(g\left(x_{k}\right)+g\left(y_{k}\right)\right) \\
= & \frac{b-a}{n} \sum_{i=1}^{k-1}\left(p_{i-1}+p_{i}\right)-\frac{b-a}{n+1} \sum_{i=1}^{k-1}\left(p_{i-1}+p_{i}\right)+\frac{b-a}{n}\left(p_{k-1}+p_{k}^{*}\right) \\
& -\frac{b-a}{n+1}\left(p_{0}+p_{0}\right)-\left(x_{k}-y_{k}\right)\left(p_{k-1}+p_{k}^{*}\right) \\
< & \frac{b-a}{n(n+1)} \sum_{i=1}^{k-1}\left(2 p_{0}\right)+\frac{b-a}{n}\left(p_{k-1}+p_{k}^{*}\right)-\frac{b-a}{n+1}\left(2 p_{0}\right) \\
& -k \frac{b-a}{n(n+1)}\left(p_{k-1}+p_{k}^{*}\right) \\
= & \frac{b-a}{n(n+1)} 2 p_{0}(k-1)-\frac{b-a}{n+1}\left(2 p_{0}\right)+\frac{b-a}{n(n+1)}(n+1-k)\left(p_{k-1}+p_{k}^{*}\right) \\
< & \frac{b-a}{n(n+1)} 2 p_{0}(k-1)-\frac{b-a}{n+1}\left(2 p_{0}\right)+\frac{b-a}{n(n+1)}(n+1-k)\left(2 p_{0}\right) \\
= & 0,
\end{aligned}
$$

maka $T\left(g, P_{n}^{1}\right)-T\left(g, P_{n+1}^{1}\right)<0$.

Kemudian, akan diperlihatkan $T\left(g, P_{n}^{2}\right)-T\left(g, P_{n+1}^{2}\right)<0$.

$$
\begin{aligned}
2 T\left(g, P_{n}^{2}\right) & =\left(x_{k+1}-x_{k}\right)\left(p_{k}^{*}+p_{k+1}^{*}\right), \\
2 T\left(g, P_{n+1}^{2}\right) & =\left(y_{k+1}-x_{k}\right)\left(p_{k}^{*}+v\right)+\left(x_{k+1}-y_{k+1}\right)\left(v+p_{k+1}^{*}\right) \\
& =p_{k}^{*}\left(y_{k+1}-x_{k}\right)+v\left(x_{k+1}-x_{k}\right)+p_{k+1}^{*}\left(x_{k+1}-y_{k+1}\right),
\end{aligned}
$$

dan mengingat bahwa $p_{k}<p_{k}^{*}<p_{k-1}$ dan $p_{k+1}<p_{k+1}^{*}<p_{k+2}$, sehingga diperoleh

$$
\begin{gathered}
\left|p_{k}^{*}-v\right| \leq\left|p_{k}^{*}-p_{k}\right|+\left|p_{k}-v\right|<\frac{2 \varepsilon}{5}, \\
\left|p_{k+1}^{*}-v\right| \leq\left|p_{k+1}^{*}-p_{k+1}\right|+\left|p_{k+1}-v\right|<\frac{2 \varepsilon}{5} .
\end{gathered}
$$

Oleh sebab itu,

$$
\begin{aligned}
2 T\left(g, P_{n}^{2}\right) & -2 T\left(g, P_{n+1}^{2}\right) \\
= & p_{k}^{*}\left(x_{k+1}-y_{k+1}\right)+p_{k+1}^{*}\left(y_{k+1}-x_{k}\right)-v\left(x_{k+1}-x_{k}\right) \\
= & \left(p_{k}^{*}-v\right)\left(x_{k+1}-y_{k+1}\right)+\left(p_{k+1}^{*}-v\right)\left(y_{k+1}-x_{k}\right) \\
& <\frac{2 \varepsilon}{5}\left(x_{k+1}-x_{k}\right) \\
& <\frac{2 \varepsilon}{5} \delta \\
\leq & \frac{\varepsilon}{5}
\end{aligned}
$$


$<\varepsilon$,

akibatnya $T\left(g, P_{n}^{2}\right)-T\left(g, P_{n+1}^{2}\right) \leq 0$.

Terakhir, akan diperlihatkan $T\left(g, P_{n}^{3}\right)-T\left(g, P_{n+1}^{3}\right)<0$.

$2 T\left(g, P_{n}^{3}\right)-2 T\left(g, P_{n+1}^{3}\right)$

$$
\begin{aligned}
= & \frac{b-a}{n} \sum_{i=k+2}^{n}\left(g\left(x_{i-1}\right)+g\left(x_{i}\right)\right)-\frac{b-a}{n+1} \sum_{i=k+3}^{n+1}\left(g\left(y_{i-1}\right)+g\left(y_{i}\right)\right) \\
& -\left(y_{k+2}-x_{k+1}\right)\left(g\left(x_{k+1}\right)+g\left(y_{k+2}\right)\right) \\
= & \frac{b-a}{n} \sum_{i=k+3}^{n}\left(p_{i-1}+p_{i}\right)-\frac{b-a}{n+1} \sum_{i=k+3}^{n}\left(p_{i-1}+p_{i}\right)+\frac{b-a}{n}\left(p_{k+1}^{*}+p_{k+2}\right) \\
& -\frac{b-a}{n+1}\left(p_{n}+p_{n}\right)-\left(y_{k+2}-x_{k+1}\right)\left(p_{k+1}^{*}+p_{k+2}\right) \\
< & \frac{b-a}{n(n+1)} \sum_{i=k+3}^{n}\left(2 p_{n}\right)+\frac{b-a}{n}\left(p_{k+1}^{*}+p_{k+2}\right)-\frac{b-a}{n+1}\left(2 p_{n}\right) \\
& -(n-k-1) \frac{b-a}{n(n+1)}\left(p_{k+1}^{*}+p_{k+2}\right) \\
= & \frac{b-a}{n(n+1)} 2 p_{n}(n-k-2)-\frac{b-a}{n+1}\left(2 p_{n}\right)+\frac{b-a}{n(n+1)}(k+2)\left(p_{k+1}^{*}+p_{k+2}\right) \\
< & \frac{b-a}{n(n+1)} 2 p_{n}(n-k-2)-\frac{b-a}{n+1}\left(2 p_{n}\right)+\frac{b-a}{n(n+1)}(k+2)\left(2 p_{n}\right) \\
= & 0,
\end{aligned}
$$

maka $T\left(g, P_{n}^{3}\right)-T\left(g, P_{n+1}^{3}\right)<0$.

Selanjutnya, mengacu pada partisi $P_{n}$ dan $P_{n+1}$, perhatikan bahwa

$$
\begin{aligned}
T_{n}(g)= & \frac{b-a}{n} \sum_{i=1}^{n} \frac{\left(g\left(x_{i-1}\right)+g\left(x_{i}\right)\right)}{2}=T\left(g, P_{n}^{1}\right)+T\left(g, P_{n}^{2}\right)+T\left(g, P_{n}^{3}\right) \text { dan } \\
T_{n+1}(g)= & \frac{b-a}{n+1} \sum_{i=1}^{n+1} \frac{\left(g\left(y_{i-1}\right)+g\left(y_{i}\right)\right)}{2} \\
= & \frac{b-a}{n+1} \sum_{i=1}^{k} \frac{\left(g\left(y_{i-1}\right)+g\left(y_{i}\right)\right)}{2}+\left(y_{k+1}-y_{k}\right)\left(p_{k-1}+v\right)+ \\
& \left(y_{k+2}-y_{k+1}\right)\left(v+p_{k+2}\right)+\frac{b-a}{n+1} \sum_{i=k+3}^{n+1} \frac{\left(g\left(y_{i-1}\right)+g\left(y_{i}\right)\right)}{2}
\end{aligned}
$$




$$
\begin{aligned}
= & {\left[\frac{b-a}{n+1} \sum_{i=1}^{k} \frac{\left(g\left(y_{i-1}\right)+g\left(y_{i}\right)\right)}{2}+\left(x_{k}-y_{k}\right)\left(p_{k-1}+p_{k}^{*}\right)\right]+} \\
& {\left[\left(y_{k+1}-x_{k}\right)\left(p_{k}^{*}+v\right)+\left(x_{k+1}-y_{k+1}\right)\left(v+p_{k+1}^{*}\right)\right]+} \\
& {\left[\left(y_{k+2}-x_{k+1}\right)\left(p_{k+1}^{*}+p_{k+2}\right)+\frac{b-a}{n+1} \sum_{i=k+3}^{n+1} \frac{\left(g\left(y_{i-1}\right)+g\left(y_{i}\right)\right)}{2}\right] } \\
= & T\left(g, P_{n+1}^{1}\right)+T\left(g, P_{n+1}^{2}\right)+T\left(g, P_{n+1}^{3}\right) .
\end{aligned}
$$

Oleh karena itu, serta menggunakan ketiga fakta di atas, maka $T_{n}(g)<T_{n+1}(g)$.

\subsection{Kemonotonan Ekor Barisan Jumlah Trapesium dari Hampiran Fungsi Monoton}

Fungsi konveks $f$ pada $[a, b]$ yang digunakan pada pembuktian proposisi 1 , memuat fungsi konveks yang monoton turun pada $[a, c)$ dan selanjutnya berupa fungsi konveks yang monoton naik pada $[c, b]$. Namun, bila difokuskan hanya pada fungsi konveks yang monoton pada $[a, b]$, maka sifat kemonotonan ekor barisan dari jumlah trapesium, yakni $\left\{T_{n}(g)\right\}_{n=N}^{\infty}$ juga berupa barisan yang naik. Berdasarkan pembuktian di atas, misalkan $f$ fungsi konveks yang turun pada $[a, b]$, maka terdapat fungsi kontinu dan linear sesepenggal $g \in C[a, b]$ dengan

$$
g\left(x_{j-1}\right)=g\left(y_{j}\right)=p_{j-1}, j=1,2, \ldots, n,
$$

dan jika $f$ berupa fungsi konveks yang naik pada $[a, b]$, maka juga terdapat fungsi linear sesepenggal $g \in C[a, b]$ dengan

$$
g\left(y_{j}\right)=g\left(x_{j}\right)=p_{j}, j=1,2, \ldots, n,
$$

sehingga keduanya baik $f$ fungsi konveks yang turun saja ataupun naik saja, dengan mudah dapat diperiksa bahwa $\|f-g\|_{\infty}<\varepsilon$ dan $T_{n}(g)<T_{n+1}(g), \forall n \geq N$.

\section{SIMPULAN}

Setiap fungsi $f$ yang kontinu dan konveks di $C[a, b]$ dapat dihampiri oleh fungsi linear sesepenggal $g$ di $C[a, b]$ sehingga ekor barisan dari jumlah trapesium $\left\{T_{n}(g)\right\}_{n=1}^{\infty}$ adalah monoton naik.

\section{DAFTAR PUSTAKA}

Bartle, R. G., \& Shertbert, D. R. (2010). Introduction to Real Analysis (4th ed.). New Jersey, USA: J Wiley.

Bennet, G., \& Jameson, G. (2000). Monotonic Avarages of Convex Function. Mathematical Analysis and Applications, 252(1), 410-430. doi:10.1006/jmaa.s000.7887.

Chatterjee, D. (2007). Topology: General and Algebraic. New Delhi, India: New Age International Limited.

Cheney, W., \& Kincaid, D. (2008). Numerical Mathematics And Computing (6th ed.). Texas, USA: Thomson Higher Education.

Kyrezi, I. (2010). Monotonicity properties of Darboux sums. Real Analysis Exchange, 35(1), 


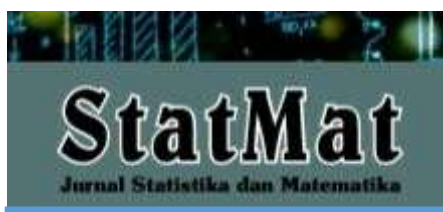

P-ISSN: 2655-3724 E-ISSN: 2720-9881

STATMAT (Jurnal Statistika dan Matematika), Vol. 3, No. 1, January 2021

Artikel ke-5, Halaman: 39-48

@Prodi S-1 Matematika FMIPA Unpam

43-64. doi:10.14321/realanalexch.35.1.0043.

Stewart, J. (2010). Calculus: Early Transcendentals (7th ed.). Boston, USA:Cengage Learning. 